\title{
Self-Efficacy for Coping with Cancer Enhances the Effect of Reiki Treatments During the Pre-Surgery Phase of Breast Cancer Patients
}

\author{
ANDREA CHIRICO ${ }^{1}$, GIUSEPPE D'AIUTO $^{2}$, ANTONELLA PENON $^{3}$, LUCA MALLIA $^{4}$, \\ MICHELINO DE LAURENTIIS $^{5}$, FABIO LUCIDI ${ }^{1}$, GERARDO BOTTI $^{6}$ and ANTONIO GIORDANO ${ }^{3,7}$ \\ ${ }^{1}$ Department of Developmental and Social Psychology, "La Sapienza" University of Rome, Rome, Italy; \\ ${ }^{2}$ ALTS - Associazione Lotta ai Tumori al Seno, Naples, Italy; \\ ${ }^{3}$ Sbarro Institute for Cancer Research and Molecular Medicine, Center for Biotechnology, \\ College of Science and Technology, Temple University, Philadelphia, PA, U.S.A.; \\ ${ }^{4}$ Departments of Movement, Human and Health Sciences, "Foro Italico" University of Rome, Rome, Italy; \\ ${ }^{5}$ Department of Senology, National Cancer Institute G. Pascale Foundation, Naples, Italy; \\ ${ }^{6}$ Department of Pathology, National Cancer Institute G. Pascale Foundation, Naples, Italy; \\ ${ }^{7}$ Deparment of Medicine, Surgery and Neuroscience, University of Siena, Siena, Italy
}

\begin{abstract}
Background/Aim: Self-efficacy for coping with cancer plays a critical role in influencing psychological cancerrelated outcomes, some studies suggested its role in enhancing or reducing the effects of psychological interventions in cancer patients. Reiki has recently been included among the efficacious complementary therapeutic intervention for cancer patients. Patients and Methods: The present study evaluated the role of self-efficacy for coping with cancer as buffer of the Reiki treatment effects on cancer- related symptoms in a randomized controlled trial (intervention versus control group) of breast cancer patients $(N=110)$ during the pre-surgery phase. Results: Results showed that self-efficacy for coping with cancer can influence the effect of a Reiki treatment. Higher efficacious patients showed a more powerful effect of the Reiki intervention on both anxiety and mood than the low efficacious patients. Conclusion: From a practical perspective, the study provides insightful results for healthcare professionals.
\end{abstract}

Breast Cancer is one of the leading causes of death among women all over the world (1). About $50-70 \%$ of cancer

This article is freely accessible online.

Correspondence to: Antonio Giordano, Sbarro Institute for Cancer Research and Molecular Medicine, Center for Biotechnology, College of Science and Technology, BioLife Science Bldg. Suite 4311900 N. 12th Street, Philadelphia, PA 19122, Temple University, Philadelphia, PA, U.S.A. Tel: +1 2152049520, Fax: +1 2152049522,e-mail: giordano@temple.edu

Key Words: Self-efficacy, cancer, Reiki, CAM, surgery. patients suffer from anxiety, depression and suicidal tendency $(2,3)$, in different phases of the treatment. This could also be the result of different cancer treatments $(4,5)$. Scientific literature demonstrates that moderate to high levels of psychosocial distress appears early during the cancer diagnosis process (4-6). In those phases seems very important to evaluate the stress of patients in order to apply targeted intervention to prevent psychiatric disorders that will persist long term in life $(3,7,8)$.

Among many interventions to reduce anxiety during the critical phases of cancer diagnosis and treatment, Complementary Alternative Medicine (CAM) has shown a broader diffusion and many scientific studies designed to evaluate its impact on the response of patients. Compared with the general population, the rate of CAM use among individuals with cancer is high (9). Reiki has recently been included among the complementary therapeutic programs derived from eastern health and healing traditions for coping with cancer (10). A recent study stated that only $8.5 \%$ of 2047 subjects enrolled in a Breast Cancer study use Reiki therapy as a CAM (11). While Reiki is traced to origins in Japan, the philosophical and basic theoretical interpretation of both techniques is steeped in ancient, pre-scientific ideas or beliefs about the "flow of a psychic form of energy". Dr. Mikao Usui rediscovered the roots of Reiki in the early 1900s. Reiki was an ancient Tibetan healing art based on the laying of hands healing tradition. Dr. Usui instructed Dr. Chujiro Hayashi in the use of the technique, who then taught Hawayo Takato. She brought Reiki to Hawaii (and mainland United States) during the 1940s. Reiki was introduced to Europe in the 1980s. Reiki today is a system of natural healing techniques 
administered by laying of hands and transferring energy from the Reiki practitioner to the recipient. It claims to enhance the body's natural ability to heal itself through the rebalancing of energy and thus restores physical, emotional, mental, and spiritual well-being (12). At this time different researches showed Reiki's efficacy on different psychological variables as anxiety, quality of life, and pain $(9,13)$ during cancer related treatments or surgery (14). Nonetheless also from a biological point of view a study stated the efficacy of Reiki in reducing stress response by analyzing comprehensively the sympathetic nervous system, the neuroendocrine response as well as the immune system (15). The authors showed significant difference comparing before and after a Reiki session in the level of Salivary Immunoglobin concentration (sIgA). The sIgA levels rose after the treatment, indicating a possible increase in immune function. Results showed also a significant drop in systolic blood pressure (SBP), conversely Skin temperature increased and electromyograph (EMG) decreased during the treatment, but before and after the treatment.

From a psychological and individual perspective, differences in coping strategies mitigate or exacerbate distress over time in cancer patients by engaging several mechanisms. For example, disengagement and denial of coping tend to undo the positive effects of optimism on stress in a Structural Equation mediated Model (SEM) of adjustment to breast cancer (16). Also, in a longitudinal model in breast cancer patients, emotionally expressive coping was associated with better physical outcomes and reductions in perceived stress (17). In social learning theory, Bandura (18) defined self-efficacy as people's belief in their abilities to generate the motivation, harness the resources, and exercise the action needed to influence events that affect their lives. Summarizing, it is the belief in one's capabilities to produce desirable outcomes (19). Along those lines, selfefficacy for coping with cancer, that is the expectations about the ability to cope with cancer, plays a critical role in influencing cancer-related outcomes including anxiety, directly or indirectly $(4,20,21)$. There is a negative relationship between perceived self-efficacy for coping with cancer and anxiety in cancer patients $(4,20-25)$ and, specifically, in breast cancer patients $(4,26)$. Recently different studies are showing an extension of the role of selfefficacy, specifically in cancer patients, as statistic moderator of the effect of cancer stressors (27), and also in moderating the effect of intervention in breast cancer patients (28). Namkoong et al., (2010) (28) in their study found that selfefficacy statistically moderated the efficacy of a Computer Mediated Social Support (CMSS) intervention in breast cancer patients. Patients with higher self-efficacy seem to accrue emotional benefits from the CMSS than patients with lower self-efficacy, in whose a negative effect on their emotional well-being was found.
According to this perspective, cancer patients with high selfefficacy expectations are better able to manage their personal functioning, harness the resources and influence the effect of a supporting treatment on their psychological well-being than patients with low self-efficacy. Thus, self-efficacy for coping, which has been studied primarily in the context of curative oncology care, and in palliative care as well (29), may play an important role also in enhancing or reducing the effect of stress target treatments in which the active role of the cancer patients can operate as a buffer of efficacy of the intervention.

There are no studies revealing the effect of Reiki intervention on breast cancer patients during "surgery phases" on related symptoms, nonetheless trying to evaluate the role of self-efficacy for coping with cancer as statistic moderator of the effect of the treatment. The main aim of this study is to evaluate Reiki intervention in reducing cancer related symptoms (i.e. anxiety and mood) in a randomized controlled trial of breast cancer patients during the pre-surgery phase (intervention vs control group). Secondarily the study evaluates for the possible influence of self-efficacy for coping with cancer as statistic moderator of the effect of the Reiki treatment on the psychological stress outcomes (i.e. anxiety and mood).

The main hypothesis of the study is that the patients in the intervention group would have a reduction of the perceived anxiety and an improvement in the mood (H1).

The second hypothesis of the study is that patients with high self-efficacy would have a lower levels of perceived anxiety and more positive mood states (H2).

Furthermore, since self-efficacy for coping, may play a role also as statistic moderator of anxiety target treatments, we also hypothesized that patients with high self-efficacy will drawn more benefits from the Reiki treatment on the anxiety variables $(\mathrm{H} 3)$.

\section{Patients and Methods}

This study was conducted at the Breast Oncology Department of the National Cancer Institute 'Giovanni Pascale' Foundation in Naples, Italy. Medical consultants identified 110 newly diagnosed breast cancer patients during the period from January to April 2015. All patients were recruited during their hospitalization. These patients were admitted to hospital for examination and were then scheduled for surgery within 1-3 days. At the time of admission, the specific type of surgery that would be performed (e.g., Lumpectomy, Quadrantectomy, or Mastectomy) had not been determined. Also none of these patients had previously received adjuvant chemotherapy or any other cancer treatments (i.e., surgery or radiotherapy). Demographic information, staging data, and family history of breast cancer were collected from medical records after obtaining informed consent. All patients $(\mathrm{N}=110)$ consented to be enrolled in the study. In the final sample, age ranged from 23 to 65 years $($ Mean age $=43.69$; $\mathrm{sd}=10.01)$.

Procedures. All patients were approached by a psychologist who described the research project and presented the informed consent form, together with a document with written information. After 
giving consent the Intervention group was scheduled for a Reiki session the day before the surgical procedure (Intervention group $\mathrm{N}=55$ ). The Reiki sessions was administered by a Reiki master and lasted about 60 mins. The standard care group did not receive reiki session $(\mathrm{N}=55)$.

Before the reiki session (T1) a booklet of different questionnaires listed in the next section were administered by the first author (a psychologist trained in conducting diagnostic interviews). The same booklet was conducted also after the session before going to sleep (T2). The control group filled the questionnaire at the same timing of as the intervention group during the day before the surgery (T1) and before going to sleep (T2).

Measures. The interviews were based on the administration of the following measures.

Cancer Behavior Inventory Brief Form, Italian version. The Cancer Behavior Inventory-Brief-Italian form is a 14-item measure of selfefficacy expectations about coping with cancer $(21,27)$. The scale is composed by four factors labeled: "independence and maintaining a positive attitude", "participation in their medical care", "coping and stress management", "management of affect". A global score of the self-efficacy for coping with cancer of the patient can be calculated by summing all the item scores. Participants report their level of confidence to perform each coping behavior on a nine-point Likert-type scale ("not at all confident" to "totally confident"); item scores were summed to form the global score. Alpha for this scale was 0.94 in the original validation study. Internal consistency of the factors is very high in the present sample (Cronbach alphas ranging between 0.87 and 0.92 ; global score 0.93 ).

Mood State. Mood state was measured by the Profile of Mood States (POMS) inventory (30). The scale measures six mood or affective states: tension/anxiety, depression/dejection, anger/hostility, vigor/activity, fatigue/inertia, and confusion/bewilderment. A total mood score, either negative or positive, can be determined by summing all the scores. Fiftyeight, five-point Likert-type scales describe the mood states. (Cronbach's alpha ranging from: $0.82-0.90$ in the present sample).

Anxiety. Anxiety was measured by the state form of the State-Trait Anxiety Inventory [STAI Form Y; (31)]. The scale is composed by 20 items, each was rated on a four-point Likert scale ranging from 0 (almost never) to 3 (almost always). The scale showed a good reliability based on the data in this study (Cronbach's alpha=0.87). Item scores for each were averaged to form an anxiety score with higher values indicating more anxiety.

Ethical considerations. The ethics committee of the National Cancer Institute 'Giovanni Pascale' Foundation approved the study (n.29/11). Informed consent was obtained from all participants. Data were confidentially gathered and collected anonymously with a smart code used to refer to the case. The voluntary nature of the study was emphasized and the authors have no conflicts of interest to report in the conduct of this study.

\section{Results}

Firstly a $2 \times 2 \times 2$ mixed ANOVA were performed using SPSS (Version 22), considering as dependent variables the level of anxiety measured by the STAI and as independent variables a "within subjects" factor, namely TIME ("T1" versus "T2"), and two "between subjects" factors, namely INTERVENTION ("Reiki" versus "control group") and SELF-EFFICACY LEVEL (Low Level vs. High Level). A $2 \times 2 \times 2$ mixed MANOVA, was instead performed considering as dependent variables the level of the six mood or affective states measured by the POMS (i.e. tension/anxiety, depression/dejection, anger/hostility, vigor/activity, fatigue/inertia, and confusion/ bewilderment) and the same independent variables of the ANOVA.

Table I reports the univariate effects of the MANOVA analysis. Finally, in the following results' sections for simplicity we described in details, both for ANOVA and for MANOVA, the effects related to the specific hypotheses of the study, namely the interaction effect between TIME and INTERVENTION (H1), the main effect of the SELFEFFICACY LEVEL (H2), and the interaction effect of TIME, INTERVENTION, and the SELF-EFFICACY LEVEL (H3). For these latter interactions' effects, the univariate or multivariate simple effects were also analyzed and described.

The effects of Time, Intervention and Self-Efficacy on patients' anxiety. As reported in Table II, overall the results of the ANOVA showed significant differences between the two groups for all the independent variables considered and their interactions on the patients' level of anxiety measured by STAI.

Overall the patients with relatively high self-efficacy reported lower levels of perceived anxiety (Mean $\pm \mathrm{sd}=$ $36.85 \pm 16.09)$ than patients with relatively low levels of selfefficacy (Mean \pm sd=58.92 \pm 14.69 ). Additionally, an interaction between the TIME and the INTERVENTION factors emerged, specifically, patients participating to the Reiki intervention showed a significant decrement (simple effect: $\left.\mathrm{F}_{(1,95)}=183.48 ; p<0.001 ; \eta_{\mathrm{p}}{ }^{2}=0.659\right)$ in their level of anxiety across the time $\left(\right.$ Mean $\pm \mathrm{sd}_{\mathrm{T} 1}=52.22 \pm 10.88 ;$ Mean $_{\mathrm{s}} \mathrm{sd}_{\mathrm{T} 2}=$ $38.46 \pm 10.08)$. Conversely, the patients of control group reported a slight, but statistically significant (simple effect: $\left.\mathrm{F}_{(1,95)}=24.927 ; p<0.001 ; \eta_{\mathrm{p}}{ }^{2}=0.208\right)$, exacerbation in their level of anxiety in the same time frame $\left(\operatorname{Mean}_{\mathrm{SSd}}^{\mathrm{T} 1}=\right.$ 51.63 \pm 16.91 ; Mean $\pm \mathrm{sd}_{\mathrm{T} 2}=57.50 \pm 20.35$ ).

Finally, the results of the ANOVA attested a TIME per INTERVENTION per SELF-EFFICACY LEVEL moderation effect. More specifically, as depicted in Figure 1, the patients of the intervention group which reported high-self-efficacy showed, across the time, a significant larger decrement ( simple effect: $\mathrm{F}_{(1,95)}=293.578 ; p<0.001 ; \eta_{\mathrm{p}}{ }^{2}=0.756$ ) in their level of anxiety in comparison with the decrement showed by patients with low self-efficacy (simple effect: $\mathrm{F}_{(1,95)}=30.040$; $\left.p<0.001 ; \eta_{\mathrm{p}}{ }^{2}=0.240\right)$. With respect the control group, moreover, the patients with high self-efficacy showed no differences in their level of anxiety across time (simple effect: $\left.\mathrm{F}_{(1,95)}=2.462 ; p=0.120 ; \eta_{\mathrm{p}}{ }^{2}=0.025\right)$, while the patients of the 
Table I. Univariate effects for the MANOVA analysis.

\begin{tabular}{|c|c|c|c|c|c|}
\hline Dependent variables & Effects & DF & $\mathrm{F}$ & $p$-Value & $\eta_{\mathrm{p}}^{2}$ \\
\hline \multirow[t]{7}{*}{ Tension } & INTERVENTION & 1,50 & 2.701 & 0.107 & 0.051 \\
\hline & SELF-EFFICACY LEVEL & 1,50 & 0.119 & 0.732 & 0.002 \\
\hline & INTERVENTION * SELF-EFFICACY LEVEL & 1,50 & 0.008 & 0.931 & 0.000 \\
\hline & TIME & 1,50 & 40.296 & $<0.001$ & 0.446 \\
\hline & TIME $*$ INTERVENTION & 1,50 & 92.240 & $<0.001$ & 0.649 \\
\hline & TIME * SELF-EFFICACY LEVEL & 1,50 & 21.877 & $<0.001$ & 0.304 \\
\hline & TIME * INTERVENTION * SELF-EFFICACY LEVEL & 1,50 & 11.090 & 0.002 & 0.182 \\
\hline \multirow[t]{7}{*}{ Depression } & INTERVENTION & 1,50 & 2.225 & 0.142 & 0.043 \\
\hline & SELF-EFFICACY LEVEL & 1,50 & 0.200 & 0.656 & 0.004 \\
\hline & INTERVENTION * SELF-EFFICACY LEVEL & 1,50 & 1.060 & 0.308 & 0.021 \\
\hline & Time & 1,50 & 0.148 & 0.702 & 0.003 \\
\hline & TIME $*$ INTERVENTION & 1,50 & 13.277 & 0.001 & 0.210 \\
\hline & TIME * SELF-EFFICACY LEVEL & 1,50 & 20.634 & $<0.001$ & 0.292 \\
\hline & TIME * INTERVENTION * SELF-EFFICACY LEVEL & 1,50 & 5.627 & 0.022 & 0.101 \\
\hline \multirow[t]{7}{*}{ Anger } & INTERVENTION & 1,50 & 5.347 & 0.025 & 0.097 \\
\hline & SELF-EFFICACY LEVEL & 1,50 & 0.162 & 0.689 & 0.003 \\
\hline & INTERVENTION $*$ SELF-EFFICACY LEVEL & 1,50 & 0.827 & 0.368 & 0.016 \\
\hline & TIME & 1,50 & 14.759 & $<0.001$ & 0.228 \\
\hline & TIME $*$ INTERVENTION & 1,50 & 52.210 & $<0.001$ & 0.511 \\
\hline & TIME * SELF-EFFICACY LEVEL & 1,50 & 6.618 & 0.013 & 0.117 \\
\hline & TIME * INTERVENTION * SELF-EFFICACY LEVEL & 1,50 & 3.044 & 0.087 & 0.057 \\
\hline \multirow[t]{7}{*}{ Vigor } & INTERVENTION & 1,50 & 0.316 & 0.576 & 0.006 \\
\hline & SELF-EFFICACY LEVEL & 1,50 & 2.169 & 0.147 & 0.042 \\
\hline & INTERVENTION * SELF-EFFICACY LEVEL & 1,50 & 0.216 & 0.644 & 0.004 \\
\hline & TIME & 1,50 & 0.670 & 0.417 & 0.013 \\
\hline & TIME * INTERVENTION & 1,50 & 5.188 & 0.027 & 0.094 \\
\hline & TIME * SELF-EFFICACY LEVEL & 1,50 & 1.158 & 0.287 & 0.023 \\
\hline & TIME * INTERVENTION * SELF-EFFICACY LEVEL & 1,50 & 6.461 & 0.014 & 0.114 \\
\hline \multirow[t]{7}{*}{ Fatigue } & INTERVENTION & 1,50 & 3.294 & 0.076 & 0.062 \\
\hline & SELF-EFFICACY LEVEL & 1,50 & 0.943 & 0.336 & 0.019 \\
\hline & INTERVENTION * SELF-EFFICACY LEVEL & 1,50 & 2.581 & 0.114 & 0.049 \\
\hline & TIME & 1,50 & 49.406 & $<0.001$ & 0.497 \\
\hline & TIME * INTERVENTION & 1,50 & 128.535 & $<0.001$ & 0.720 \\
\hline & TIME * SELF-EFFICACY LEVEL & 1,50 & 3.501 & 0.067 & 0.065 \\
\hline & TIME * INTERVENTION * SELF-EFFICACY LEVEL & 1,50 & .226 & 0.637 & 0.004 \\
\hline \multirow[t]{7}{*}{ Confusion } & INTERVENTION & 1,50 & 2.202 & 0.144 & 0.042 \\
\hline & SELF-EFFICACY LEVEL & 1,50 & 4.251 & 0.044 & 0.078 \\
\hline & INTERVENTION * SELF-EFFICACY LEVEL & 1,50 & 5.788 & 0.020 & 0.104 \\
\hline & TIME & 1,50 & 7.066 & $<0.001$ & 0.497 \\
\hline & TIME * INTERVENTION & 1,50 & 67.066 & $<0.001$ & 0.573 \\
\hline & TIME * SELF-EFFICACY LEVEL & 1,50 & 10.377 & 0.002 & 0.172 \\
\hline & TIME * INTERVENTION * SELF-EFFICACY LEVEL & 1,50 & 2.619 & 0.112 & 0.050 \\
\hline
\end{tabular}

same group with low self-efficacy showed a significant improvement in their anxiety (simple effect: $F_{(1,95)}=109.432$; $\left.p<0.001 ; \eta_{\mathrm{p}}^{2}=0.535\right)$.

The effects of Time, Intervention and Self-Efficacy on patients' mood. As reported in Table III, overall the results of the MANOVA showed significant multivariate effects on patients' mood states measured by the POMS for the "within subject" factor namely TIME, and for the interaction between TIME and the "between subjects" factors (i.e.
INTERVENTION and SELF-EFFICACY LEVEL). With respect to the SELF-EFFICACY LEVEL, overall, the patients with high level of self-efficacy did not report significantly different level of mood states, then patients with low level of self-efficacy did.

A significant multivariate interaction effect between TIME and INTERVENTION emerged (H1). Analyzing the univariate effects reported in Table I, this interaction effect was statistically significant for all the six mood dimensions measured by the POMS. Analyzing the multivariate simple effect associated to 
Table II. Results of the ANOVA.

\begin{tabular}{|c|c|c|c|c|c|}
\hline Effects & & DF & $\mathrm{F}$ & $p$-Value & $\eta_{p}^{2}$ \\
\hline \multirow[t]{3}{*}{ Between subjects } & INTERVENTION & 1,94 & 7.570 & 0.007 & 0.075 \\
\hline & SELF-EFFICACY LEVEL & 1,94 & 26.004 & $<0.001$ & 0.217 \\
\hline & GROUP * SELF-EFFICACY LEVEL & 1,94 & 15.483 & $<0.001$ & 0.141 \\
\hline \multirow[t]{4}{*}{ Within subjects } & TIME & 1,94 & 38.72 & $<0.001$ & 0.290 \\
\hline & TIME * GROUP & 1,94 & 188.27 & $<0.001$ & 0.667 \\
\hline & TIME * SELF-EFFICACY LEVEL & 1,94 & 101.687 & $<0.001$ & 0.520 \\
\hline & TIME * GROUP * SELF-EFFICACY LEVEL & 1,94 & 6.918 & 0.010 & 0.069 \\
\hline
\end{tabular}

Table III. Results of the MANOVA.

\begin{tabular}{|c|c|c|c|c|c|}
\hline Effects & & Wilks' Lambda & DF & $p$-Value & $\eta_{\mathrm{p}}^{2}$ \\
\hline \multirow[t]{3}{*}{ Between subjects } & INTERVENTION & 0.887 & 6,45 & 0.463 & 0.113 \\
\hline & SELF-EFFICACY LEVEL & 0.888 & 6,45 & 0.474 & 0.112 \\
\hline & INTERVENTION * SELF-EFFICACY LEVEL & 0.859 & 6,45 & 0.311 & 0.141 \\
\hline \multirow[t]{4}{*}{ Within subjects } & TIME & 0.326 & 6,45 & $<0.001$ & 0.674 \\
\hline & TIME * INTERVENTION & 0.248 & 6,45 & $<0.001$ & 0.752 \\
\hline & TIME $*$ SELF-EFFICACY LEVEL & 0.609 & 6,45 & 0.001 & 0.391 \\
\hline & TIME * INTERVENTION * SELF-EFFICACY LEVEL & 0.715 & 6,45 & 0.015 & 0.285 \\
\hline
\end{tabular}

this interaction, patients participating to the Reiki intervention, overall, showed a significant decrement across the time (multivariate simple effect: Wilks' $\operatorname{Lambda}_{(1,95)}=0.233$; $\left.p<0.001 ; \eta_{\mathrm{p}}{ }^{2}=0.767\right)$ in their levels of negative mood $\left(\right.$ Mean $\pm \mathrm{sd}_{\text {Tension- } \mathrm{T} 1}=11.93 \pm 5.36$ and $\mathrm{Mean} \pm \mathrm{sd}_{\mathrm{Tension}-\mathrm{T} 2}=4.48 \pm$ 4.14; Mean $\pm \mathrm{sd}_{\text {Depression-T1 }}=13.14 \pm 10.89$ and Mean \pm sd $\mathrm{d}_{\text {Depression- }}$ ${ }_{\mathrm{T} 2}=7.68 \pm 9.87$; Mean $\pm \mathrm{sd}_{\text {Anger-T1 }}=14.26 \pm 10.05$ and Mean \pm $\mathrm{sd}_{\text {Anger-T2 }}=4.48 \pm 6.47 ; \quad$ Mean $\pm \mathrm{sd}_{\text {Fatigue- } \mathrm{T} 1}=11.31 \pm 6.46$ and Mean $\pm \mathrm{sd}_{\text {Fatigue }-\mathrm{T} 2}=4.96 \pm 4.12 ;{\text { Mean } \pm \mathrm{sd}_{\text {Confusion-T1 }}=10.68 \pm 5.55}$ and Mean $\pm \mathrm{ds}_{\text {Confusion-T2 }}=5.95 \pm 5.19$ ). Conversely, patients of the control group reported a statistically significant increment (multivariate simple effect: Wilks' $\operatorname{Lambda}_{(6,46)}=0.576$; $p<0.001 ; \eta_{\mathrm{p}}{ }^{2}=0.424$ ) in their levels of negative mood (Mean \pm $\mathrm{sd}_{\text {Tension- } \mathrm{T} 1}=8.91 \pm 7.67$ and $\mathrm{Mean} \pm \mathrm{sd}_{\text {Tension- } \mathrm{T} 2}=9.98 \pm 8.15$; Mean $\pm \mathrm{sd}_{\text {Depression- } 11}=13.17 \pm 11.28$ and Mean $\pm \mathrm{sd}_{\text {Depression- }}$ $\mathrm{T} 2_{2}=16.76 \pm 10.69$; Mean $\pm \mathrm{sd}_{\text {Anger-T1 }}=11.15 \pm 10.66$ and Mean \pm $\mathrm{sd}_{\text {Anger-T2 }}=13.27 \pm 10.88 ; \quad$ Mean \pm sd $_{\text {Vigor-T1 }}=14.51 \pm 6.94$ and Mean $\pm \mathrm{sd}_{\text {Vigor-T2 }}=16.49 \pm 6.38 ;$ Mean $\pm \mathrm{sd}_{\text {Fatigue-T1 }}=11.00 \pm 6.23$ and Mean $\pm \mathrm{sd}_{\text {Fatigue-T2 }}=12.58 \pm 6.17$; Mean $\pm \mathrm{sd}_{\text {Confusion- }}$ $\mathrm{T} 1=11.02 \pm 5.12$ and Mean $\pm \mathrm{sd}_{\text {Confusion- } \mathrm{T} 2}=12.93 \pm 5.05$ ).

Finally, the results of the MANOVA attested also a multivariate moderation effect of the self-efficacy on these latter effects. However, the analysis of the univariate effects reported in Table I revealed a significant effect of the interaction TIME * INTERVENTION *SELF-EFFICACY LEVEL only for Tension $\left(\mathrm{F}_{(1,50)}=11.090 ; \quad p=0.002\right.$; $\left.\eta_{\mathrm{p}}{ }^{2}=0.182\right)$, Depression $\left(\mathrm{F}_{(1,50)}=5.627 ; p=0.022 ; \eta_{\mathrm{p}}{ }^{2}=0.101\right)$ and Vigor $\left(\mathrm{F}_{(1,50)}=6.461 ; p=0.014 ; \eta_{\mathrm{p}}{ }^{2}=0.114\right)$. In particular, as depicted in Figure 2 and analyzing the simple effect associated to this interaction, the patients of the intervention group with high-self-efficacy showed, across the time, a significant larger decrement in tension (simple effect: $\left.\mathrm{F}_{(1,77)}=148.014 ; p<0.001 ; \eta_{\mathrm{p}}{ }^{2}=0.658\right)$ in comparison with the decrement showed by patients with low self-efficacy (simple effect: $\left.F_{(1,77)}=87.373 ; p<0.001 ; \eta_{p}{ }^{2}=0.532\right)$. The patients of the intervention group with high-self-efficacy showed, also a significant decrement in depression across the time (simple effect: $\left.\mathrm{F}_{(1,66)}=33.38 ; p<0.001 ; \eta_{\mathrm{p}}{ }^{2}=0.336\right)$, while the patients of the same group with low self-efficacy showed no differences across the time (simple effect: $F_{(1,66)}=2.18$; $p=0.145 ; \eta_{\mathrm{p}}{ }^{2}=0.032$ ). Finally, the patients of the intervention group with relatively higher levels of self-efficacy showed an improvement in their vigor tending to the statistical significance (simple effect: $\mathrm{F}_{(1,10)}=3.292 ; \quad p=0.074$; $\eta_{\mathrm{p}}{ }^{2}=0.045$ ), while patients of the same group with low selfefficacy did not change their vigor's level across time ( simple effect: $\mathrm{F}_{(1,70)}=0.009 ; p=0.924 ; \eta_{\mathrm{p}}{ }^{2}=0.000$ ).

With respect the control group, moreover, as reported in figure 2, the patients with high self-efficacy did not change their level of tension (simple effect: $\mathrm{F}_{(1,77)}=0.103 ; p=0.750$; $\eta_{\mathrm{p}}{ }^{2}=0.001$ ) and of depression (simple effect: $\mathrm{F}_{(1,66)}=0.015$; $\left.p=0.904 ; \eta_{\mathrm{p}}{ }^{2}=0.000\right)$ across time. Conversely the patients with low self-efficacy showed a significant increment on the level of these two negative patients moods (simple effect Tension: $\mathrm{F}_{(1,77)}=13.968 ; p<0.001 ; \eta_{\mathrm{p}}{ }^{2}=0.154$; simple effect Depression: $\left.\mathrm{F}_{(1,66)}=24.337 ; p<0.001 ; \eta_{\mathrm{p}}{ }^{2}=0.269\right)$ across the 


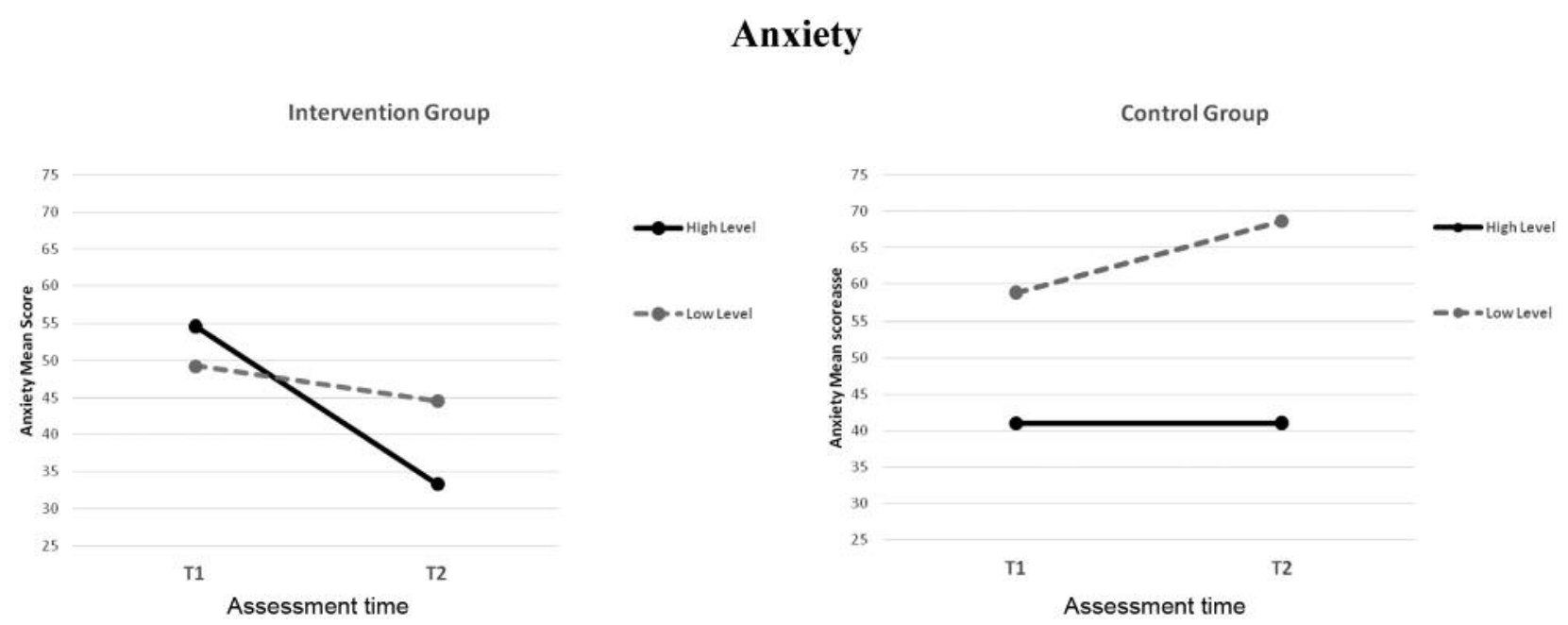

Figure 1. Anxiety mean scores across time (T1 vs. T2), self-efficacy level (High level vs. Low Level), and intervention (Intervention Group vs. Control group).

same time frame. Additionally, the analysis of the simple effects showed that patients of the control group with high levels of self-efficacy showed an increment in their vigor across the time (simple effect: $\mathrm{F}_{(1,70)}=8.128 ; p=0.006$; $\left.\eta_{\mathrm{p}}{ }^{2}=0.104\right)$, while these levels remain substantially the same (simple effect: $\mathrm{F}_{(1,70)}=1.841 ; p=0.179 ; \eta_{\mathrm{p}}{ }^{2}=0.026$ ) in patients with low self-efficacy.

\section{Discussion}

As can be seen from the rising percentage of CAM therapy used to supplement traditional Western therapeutic strategies, modern healthcare consumers have taken interest in a more holistic approach to healthcare delivery (32). The use of alternative medicine has grown exponentially since 2000. An abundance of literature has shown a reduction in anxiety, mood improvement and well-being when CAM therapies are used. Reiki therapy has been cited as a complementary therapy that is easy to learn, inexpensive, non-invasive, and associated with relaxation and pain reduction (33). In the current study, we evaluated whether Reiki therapy was able to improve mood and decrease anxiety of breast cancer patients hospitalized for surgical procedure.

According to our first hypotheses, we were able to show that patients receiving Reiki treatment had a sensitive reduction of anxiety and an improvement of the mood, conversely when patients received the standard care (control group), both increases in anxiety and decrease of the general mood were noticed. The differences showen between and within subjects suggest that Reiki intervention in breast cancer patients the day before the surgical procedure is an effective practice in improving the general patients' well- being. Not surprising our results are in line with past literature, that found similar results in cancer patients (3436 ), also in the same phase of cancer care trajectory (surgical phase) $(37,38)$.

Moreover, results of the study also confirmed the second hypotheses of this study, in fact, data showed that higher self-efficacious patients overall, receiving or not receiving the Reiki treatment, were more able to manage their anxiety than the lower self-efficacious patients. This result is completely in line with the social cognitive theory, that posits self-efficacy for coping with cancer in a strict negative relationship with stress and positive relationship with quality of life of cancer patients $(21,24)$. Therefore, also past literature results confirmed these relationships $(4,25)$.

Furthermore, in our sample, we were able to show that self-efficacy has an important role in buffering the effect of the Reiki intervention. In our study, in fact, a cancer patient more confident in his/her ability to cope with the disease related stressors, drawn better the benefits coming from the Reiki intervention than the patients with lower confidence in coping with the disease stressors.

This finding is particularly interesting, because extant previous research has observed that supportive treatment among breast cancer patients have several positive health outcomes, including psychological benefits (39), however, this study suggests that the positive effects are conditional, based on the patients' level of coping self-efficacy. Selfefficacy for coping with cancer is a state-like expectation in one's competence (40) to cope with cancer-related stressors. Both theoretical and empirical evidence suggest that cancer patients with high self-efficacy should be better-adapted and thereby less likely to have negative psychological outcomes. 


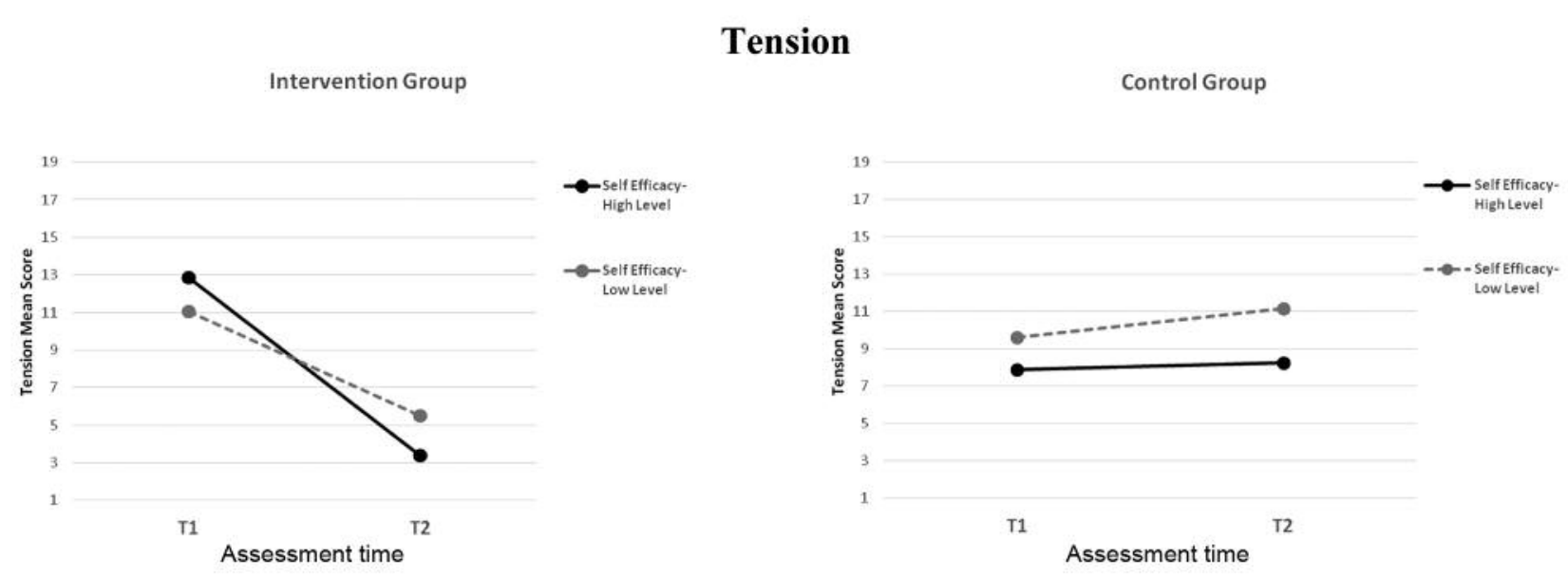

\section{Depression}

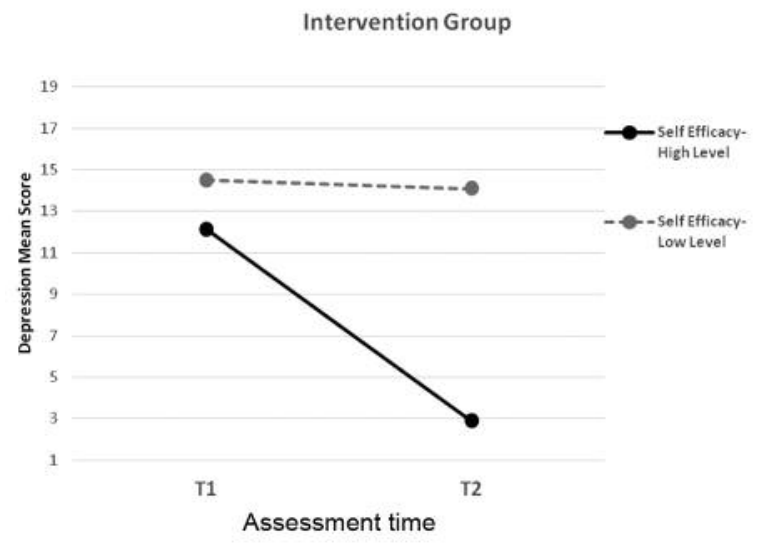

Intervention Group

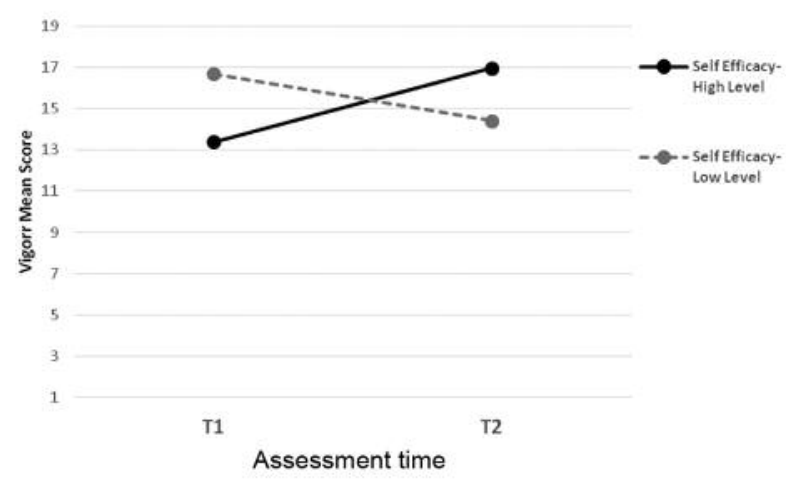

Control Group

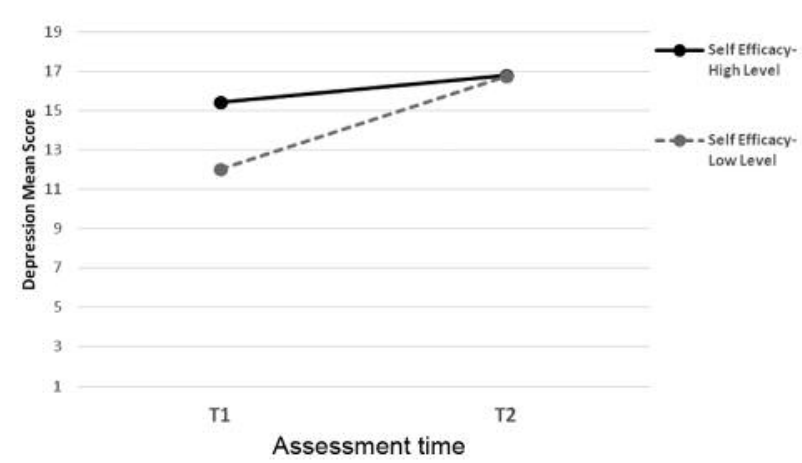

Vigor

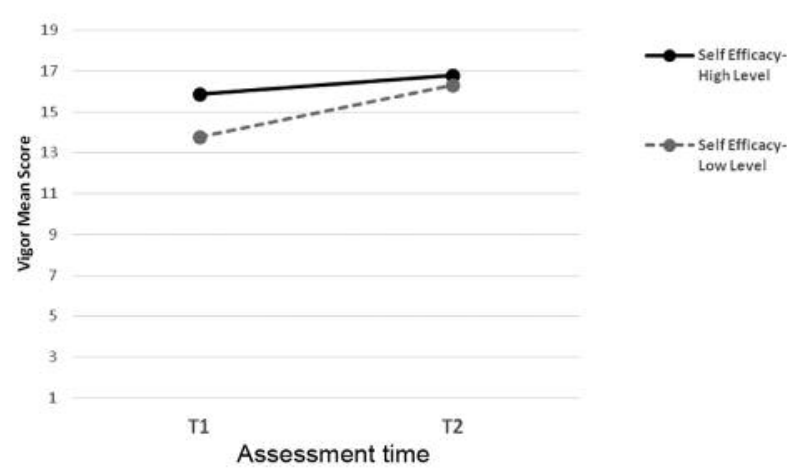

Figure 2. Tension, Depression and Vigor mean scores across time (T1 vs. T2), self-efficacy level (High level vs. Low Level), and intervention (Intervention Group vs. Control group).

In our sample of cancer patients, self-efficacy for coping with cancer may play an important role in mitigating the stressful condition of patients during the first hospitalization phase for a cancer diagnosis. The interaction analysis, in fact, revealed a critical role of self-efficacy for coping with cancer acting as buffer of the efficacy of the Reiki intervention, in our sample, patients that felt more able to cope with cancer reported an higher impact of the Reiki treatment in reducing 
the perceived anxiety than the lower efficacious patients. The potentially statistical powerful moderator role of the selfefficacy for coping with cancer fits with both the theoretical framework and with empirical data. In line with theory, a highly efficacious cancer patient may actively search for certain desired outcomes, being able to manage stress deriving from cancer diagnosis/hospitalization and either to draw as much as possible benefit from Reiki treatments

In conclusion, CAM seems to be a powerful tool able to reduce the stress of the patients since the first phases of cancer diagnosis. The present study provided insightful results about the possibility to account for individual differences (self-efficacy for coping with cancer) able to moderate the effects of a Reiki treatment on cancer patients. Seemingly patients with higher level of self-efficacy can draw more benefits by the treatment than lower efficacious patients.

Ascertained that there are available easy-administrable tools that allow clinicians and health professionals to assess the self-efficacy of coping with cancer (i.e. Cancer Behavior Inventory $(21,27)$; and that psychosocial interventions have shown great promise in improving self-efficacy for coping with cancer (41), understanding the impact of the perception of self-efficacy as it applies to health behavior, and cancer related stressors it is a new challenge for interventions paradigms. In fact, from a practical perspective, health professionals can screen patients accounting for their level of coping self-efficacy, before a Reiki treatment, then it may be possible to target low efficacious patients with an intervention to enhance self-efficacy in order to improve the effects of the Reiki treatment.

Future research should examine how coping with cancer self-efficacy is related with key outcomes in cancer trajectories, in longitudinal studies and with a larger number of participants providing evidences for interventions targeting and/or accounting for the coping with cancer selfefficacy patients level. Then effects of the Reiki treatment in longitudinal studies with different timing, at different point in the cancer trajectories, can be evaluated taking in consideration the role of the coping with cancer selfefficacy.

The limitation of the study is the small size of the sample. Although, it is enough for the analysis, could be considered low for the power of the statistical analysis.

\section{Acknowledgements}

The Authors would like to thank Reiki Masters Francesca Fallace, Cosima Portulano, and Reiki second level Pina Bora Cerciello, Virgilia Cacciola, Emilia Aversa, Mariagrazia Finiello. Andrea Chirico and Antonio Giordano were funded by Sbarro Health Research Organization (www.shro.org) and the Commonwealth of Pennsylvania, Department of Health, Biotechnology Research Program.

\section{References}

1 Forouzanfar MH, Foreman KJ, Delossantos AM, Lozano R, Lopez AD, Murray CJL and Naghavi M: Breast and cervical cancer in 187 countries between 1980 and 2010: A systematic analysis. Lancet 378: 1461-1484, 2011.

2 Singh $\mathrm{P}$ and Chaturvedi A: Complementary and alternative medicine in cancer pain management: a systematic review. Indian J Palliat Care 21: 105-115, 2015.

3 Strang P: Cancer pain - a provoker of emotional, social and existential distress. Acta Oncol 37: 641-644, 1998.

4 Chirico A, Lucidi F, Mallia L, D'Aiuto M and Merluzzi TVTV: Indicators of distress in newly diagnosed breast cancer patients. PeerJ 3: e1107, 2015.

5 Andreu Y, Galdón MJ, Durá E, Martínez P, Pérez S and Murgui S: A longitudinal study of psychosocial distress in breast cancer: prevalence and risk factors. Psychol Health 27: 72-87, 2012.

6 Nosarti C, Roberts J V, Crayford T, McKenzie K and David AS: Early psychological adjustment in breast cancer patients. J Psychosom Res 53: 1123-1130, 2002.

7 Otte JL, Davis L, Carpenter JS, Krier C, Skaar TC, Rand KL, Weaver M, Landis C, Chernyak Y and Manchanda S: Sleep disorders in breast cancer survivors. Support Care Cancer 24: 4197-4205, 2016.

8 Alkan A, Guc ZG, Senler FC, Yavuzsen T, Onur H, Dogan M, Karci E, Yasar A, Koksoy EB, Tanriverdi O, Turhal S, Urun Y, Ozkan A, Mizrak D and Akbulut H: Breast cancer survivors suffer from persistent postmastectomy pain syndrome and posttraumatic stress disorder (ORTHUS study): a study of the palliative care working committee of the Turkish Oncology Group (TOG). Support Care Cancer 24: 3747-3755, 2016.

9 Fleisher KA, Mackenzie ER, Frankel ES, Seluzicki C, Casarett D and Mao JJ: Integrative Reiki for cancer patients: a program evaluation. Integr Cancer Ther 13: 62-67, 2014.

10 DiScipio WJ: Perceived relaxation as a function of restorative yoga combined with Reiki for cancer survivors. Complement Ther Clin Pract 24: 116-122, 2016.

11 Saquib J, Madlensky L, Kealey S, Saquib N, Natarajan L, Newman VA, Patterson RE and Pierce JP: Classification of CAM use and its correlates in patients with early-stage breast cancer. Integ Cancer Ther 10: 138-147, 2011.

12 Alarcão Z and Fonseca JRS: The effect of Reiki therapy on quality of life of patients with blood cancer: results from a randomized controlled trial. Eur J Integr Med 8: 239-249, 2016.

13 Birocco N, Guillame C, Storto S, Ritorto G, Catino C, Gir N, Balestra L, Tealdi G, Orecchia C, Vito GD, Giaretto L, Donadio M, Bertetto O, Schena M and Ciuffreda L: The effects of Reiki therapy on pain and anxiety in patients attending a day oncology and infusion services unit. Am J Hosp Palliat Med 29: 290-294, 2012.

14 Alandydy P and Alandydy K: Using Reiki to support surgical patients. J Nurs Care Qual 13: 89-91, 1999.

15 Wardell DW and Engebretson J: Biological correlates of Reiki Touch(sm) healing. J Adv Nurs 33: 439-445, 2001.

16 Carver CS, Pozo C, Harris SD, Noriega V, Scheier MF, Robinson DS, Ketcham AS, Moffat FL and Clark KC: How coping mediates the effect of optimism on distress: A study of women with early stage breast cancer. J Pers Soc Psychol 65: 375-390, 1993. 
17 Stanton AL, Danoff-Burg S, Cameron CL, Bishop M, Collins CA, Kirk SB, Sworowski LA and Twillman R: Emotionally expressive coping predicts psychological and physical adjustment to breast cancer. J Consult Clin Psychol 68: 875-882, 2000.

18 Bandura A: Self-efficacy mechanism in human agency. Am Psychol 37: 122-147, 1982.

19 Bandura A, Pastorelli C, Barbaranelli C and Caprara GV: Selfefficacy pathways to childhood depression. J Pers Soc Psychol 76: 258-269, 1999.

20 Merluzzi TV, Nairn RC, Hegde K, Martinez Sanchez MA and Dunn L: Self-efficacy for coping with cancer: revision of the Cancer Behavior Inventory (version 2.0). Psychooncology 10: 206-217, 2001.

21 Heitzmann CA, Merluzzi TV, Jean-Pierre P, Roscoe JA, Kirsh KL and Passik SD: Assessing self-efficacy for coping with cancer: Development and psychometric analysis of the brief version of the Cancer Behavior Inventory (CBI-B). Psychooncology 20: 302-312, 2011.

22 Philip EJ, Merluzzi TV, Zhang Z and Heitzmann CA: Depression and cancer survivorship: importance of coping self-efficacy in post-treatment survivors. Psychooncology 22: 987-994, 2013.

23 Howsepian BA and Merluzzi TV: Religious beliefs, social support, self-efficacy and adjustment to cancer. Psychooncology 18: 1069-1079, 2009.

24 Merluzzi TV and Martinez Sanchez MA: Assessment of selfefficacy and coping with cancer: Development and validation of the Cancer Behavior Inventory. Heal Psychol 16: 163-170, 1997.

25 Chirico A, Lucidi F, Merluzzi T, Alivernini F, Laurentiis M De, Botti $G$ and Giordano A: A meta-analytic review of the relationship of cancer coping self-efficacy with distress and quality of life. Oncotarget, 2017. doi: 10.18632/ oncotarget.15758. [Epub ahead of print]

26 Henselmans I, Fleer J, de Vries J, Baas PC, Sanderman R and Ranchor AV: The adaptive effect of personal control when facing breast cancer: cognitive and behavioural mediators. Psychol Health 25: 1023-1040, 2010.

27 Chirico A, Serpentini S, Merluzzi T, Mallia L, Del Bianco P, Martino R, Trentin L, Bucci E, DE Laurentiis M, Capovilla E, Lucidi F, Botti G and Giordano A: Self-efficacy for coping moderates the effects of distress on quality of life in palliative cancer care. Anticancer Res 37: 1609-1615, 2017.

28 Namkoong K, Shah DV, Han JY, Kim SC, Yoo W, Fan D, McTavish FM and Gustafson DH: Expression and reception of treatment information in breast cancer support groups: How health self-efficacy moderates effects on emotional well-being. Patient Educ Couns 81: S41-S47, 2010.

29 Serpentini S, Merluzzi TV, Del Bianco P, Chirico A, Lucidi F, Martino R, Trentin L and Capovilla E: Self-efficacy for coping with cancer in palliative care: an italian research. In: Psychooncology. p. 184, 2016.
30 McNair DM, Lorr N and Droppleman LF: Manual for the Profile of Mood States. Educational and Industrial Testing Services, San Diego, CA, 1971.

31 Spielberger CD, Gorsuch RL, Lushene RE, Vagg PR and Jacobs GA: Manual for the state-trait anxiety inventory (rev. ed.). Palo Alto, CA: Consulting Psychologists Press, 1983.

32 Institute of Medicine (U.S.). Committee on the Use of Complementary and Alternative Medicine by the American Public.: Complementary and alternative medicine in the United States. National Academies Press, 2005.

33 Bossi LM, Ott MJ and DeCristofaro S: Reiki as a Clinical Intervention in Oncology Nursing Practice. Clin J Oncol Nurs 12: 489-494, 2008.

34 Beard C, Stason WB, Wang Q, Manola J, Dean-Clower E, Dusek JA, Decristofaro S, Webster A, Doherty-Gilman AM, Rosenthal DS and Benson $\mathrm{H}$ : Effects of complementary therapies on clinical outcomes in patients being treated with radiation therapy for prostate cancer. Cancer 117: 96-102, 2011.

35 Olson K, Hanson J and Michaud M: A phase II trial of Reiki for the management of pain in advanced cancer patients. J Pain Symptom Manage 26: 990-997, 2003.

36 Tsang KL, Carlson LE and Olson K: Pilot crossover trial of Reiki versus rest for treating cancer-related fatigue. Integr Cancer Ther 6: 25-35, 2007.

37 Potter PJ: Breast biopsy and distress. J Holist Nurs 25: 238-248, 2007.

38 Vitale AT and O'Connor PC: The effect of Reiki on pain and anxiety in women with abdominal hysterectomies: a quasiexperimental pilot study. Holist Nurs Pract 20: 263-272, 2006.

39 Witt $\mathrm{CM}$ and Cardoso MJ: Complementary and integrative medicine for breast cancer patients - Evidence based practical recommendations. Breast 28: 37-44, 2016.

40 Bandura A: Recycling misconceptions of perceived self-efficacy. Cognit Ther Res 8: 231-255, 1984.

41 Zhang M, Chan SW chi, You L, Wen Y, Peng L, Liu W and Zheng M: The effectiveness of a self-efficacy-enhancing intervention for Chinese patients with colorectal cancer: A randomized controlled trial with 6-month follow up. Int J Nurs Stud 51: 1083-1092, 2014.
Received May 12, 2017

Revised May 25, 2017

Accepted May 30, 2017 